\title{
LA OBJETIVIDAD EN LA INTERPRETACIÓN JURÍDICA. LA OBJETIVIDAD JURÍDICA MODESTA Y SUS PROBLEMAS
}

\author{
Carlos I. MASSINI CORREAS
}

Resumen:

La interpretación jurídica es un tema complejo que plantea diversos problemas, y uno de ellos, quizá el más relevante, es el relativo a establecer si las proposiciones interpretativas derivadas de un texto jurídico son objetivas. Las principales posturas existentes en torno a la posible objetividad de las proposiciones interpretativas, son analizadas y evaluadas por el autor (en especial, la llamada "objetividad modesta") para descubrir si existe un referente objetivo para las interpretaciones jurídicas, el término objetivo de esa referencia y en que consiste tal objetividad.

\section{Abstract:}

Legal interpretation is a complex subject that raises several problems, and one of them relates to the question whether legal interpretative propositions are objective. Several claims arguing in favor of this objective stance are discussed in the article with the idea of understanding the nature of such claims. 
SUMARIO: I. Introducción. II. La cuestión semántica. III. La objetividad de las proposiciones interpretativas. IV. Coleman, Leiter y la objetividad interpretativa "modesta". V. Las condiciones epistémicas ideales. VI. Valoración de la objetividad "modesta". VII. Conclusiones.

\section{INTRODUCCIÓN}

La interpretación (i.) jurídica plantea, en sede filosófica, una gran cantidad de problemas de dificil y controvertida solución, ${ }^{1}$ pero pareciera que el más complejo, intrincado y con mayores consecuencias para la vida práctica del derecho, es el que radica en establecer y precisar el carácter de objetividad —o no objetividad- de ese tipo de i. Dicho de otro modo, se trata de dar una solución racionalmente satisfactoria a la cuestión de saber si las proposiciones interpretativas, i.e., las que establecen el significado normativo de un texto juridico, tienen un referente objetivo, o bien se reducen a meras expresiones de la subjetividad del intérprete y, en la primer alternativa, cuál es el carácter o indole del objeto al que remiten las mencionadas proposiciones interpretativas.

En el pensamiento jurídico contemporáneo estas cuestiones han sido objeto de un intenso debate, en el que han tomado parte, desde distintas perspectivas, pensadores de matriz positivista, tanto "incluyentes" como "excluyentes", 2 así como varios filósofos iusnaturalistas, tanto "derivacionistas" como "inclinacionistas". ${ }^{3}$

1 Véase Guastini, R., Estudios sobre la interpretación jurídica, traducción de M. Gascón y M. Carbonell, México, Porrúa, 2003, pp. 57-70.

2 Sobre estas categorizaciones, véase Marmor, A., "Exclusive Legal Positivism", en Coleman, J. y Shapiro, S. (ed.), The Oxford Handbook of Jurisprudence and Philosophy of Law, Oxford, Oxford U.P., 2002, pp. 104 ss.; y Einar Himma, K., "Inclusive Legal Positivism", en la misma obra cita de Coleman y Shapiro, pp. 125 y ss.

3 En este punto, véase Murphy, M. C., Natural Law and Practical Rationality, Cambridge, Cambridge U.P., 2001, pp. 6-17. 
En lo que sigue, se ensayará una contribución a ese renovado debate, clarificando en primer lugar los términos precisos de la controversia, para pasar luego al análisis y valoración de los diferentes intentos de respuesta a las cuestiones planteadas y finalizar con una propuesta que pretende superar las principales aporias que se presentan al pensamiento jurídico en los términos actuales. Pero antes de establecer y concretar los términos del problema a abordar, conviene efectuar ante todo algunas aclaraciones acerca del sentido con que se utilizará la palabra objetividad en el presente trabajo, ya que es bien sabido que ella se ha utilizado y se utiliza de modo analógico y hasta equívoco, por lo que estas precisiones adquieren una especial pertinencia y una particular relevancia.

\section{LA CUESTIÓN SEMÁNTICA}

Es bien sabido que "objetividad" es un nombre abstracto que designa la cualidad formal de todo lo que es "objetivo", término que a su vez deriva, en cuanto adjetivo, del sustantivo "objeto". Este último término procede etimológicamente del término latino objectum, participio pasado de obicere, que tiene el significado de arrojado hacia, colocado enfrente, que yace frente, etcétera ${ }^{4} \mathrm{y}$, en este sentido etimológico, se distingue de - pero no se opone a- subjectum, cuyo significado originario se vincula con lo que está debajo, lo que subyace o lo que se encuentra en la base de alguna otra cosa. Es también conocido que en el latín medieval, v.gr., en la obra de Duns Scoto, subjectum designaba a la realidad en sí y objectum a esa misma realidad en cuanto conocida por el intelecto ${ }^{5}$ y que recién a partir del siglo XVIII, particularmente en la obra de Alexander Baumgartner, se

4 Véase The Oxford Dictionary of English Etymology, Onions, C. T. (ed.), Oxford, Clarendon Press, 1994, p. 620. Asimismo, véase Millán Puelles, A., Teoría del objeto puro, Madrid, Rialp, 1990, pp. 105 y ss.

5 Véase Lalande, A., Vocabulario técnico y critico de la filosofía, traducción de L. Alfonso et al., Buenos Aire, El Ateneo, 1967, p. 699. 
comenzó a designar con el término "objetivo" a lo que pertenece o corresponde a una realidad distinta o independiente del sujeto que conoce o apetece y, de modo correlativo, a referir con el término "subjetivo" a todo lo concerniente al titular del acto de conocer o querer un objeto. Este es el significado más usual en nuestros dias y el que recoge, entre muchos otros, el Diccionario de la Lengua Española de la Real Academia. 6

Por lo tanto, y siguiendo aquí el consejo de Tomás de Aquino en el sentido de que las palabras deben usarse con la significación que se les atribuye corrientemente, ${ }^{7}$ en lo que sigue se entenderá por "objeto", en un sentido estricto o restringido, a todo "aquello que está delante del sujeto con independencia del mismo y a lo cual éste debe amoldarse" 8 y por "objetivo" a lo que es propio del objeto en cuanto tal, que está en él, corresponde o se refiere a él, frente a lo que aparece como propio del sujeto. Dicho en otras palabras, lo objetivo es lo determinado desde el objeto y fundado en él, en contraposición a lo subjetivo, entendido como lo determinado únicamente por los sentimientos o afirmaciones personales del sujeto. ${ }^{9}$ En este sentido, v.gr., la afirmación de que "Monet es un pintor impresionista", es objetiva pues tiene su justificación en el objeto mismo de conocimiento, en cambio, la aserción "Monet es un pintor que me disgusta" es subjetiva, ya que no pretende fundarse en la obra de Monet, sino expresar la reacción emocional del sujeto observador frente a sus cuadros. Por su parte, con el término "objetividad" se designará a la cualidad formal de aquello que es objetivo y, en ese sentido, se hablará

6 Diccionario de la Lengua Española, Espasa Calpe, 1994, t. II, p. 1459.

7 Tomás de Aquino, Summa Contra Gentiles, I, 1. Allí escribe el Aquinate: "El uso corriente que, según cree el filósofo, ha de seguirse al denominar las cosas...".

8 Véase Vries, J. de, voz "Objeto", en varios autores, Brugger, W. (dir.), Diccionario de filosofía, traducción de J. M. Vélez Cantarell, Barcelona, Herder, 1975, p. 376.

9 Idem. En un sentido similar, Jesús García López define el objeto como todo aquello "que es término de una actividad consciente"; voz "Objeto", Gran enciclopedia Rialp, Madrid, Rialp, t. XVII, 1981, p. 169. 
de que una cierta afirmación tiene objetividad en la medida en que se refiera al elemento objetivo del objeto, o bien que tenga por referente semántico al objeto mismo en su calidad de tal objeto, especialmente en cuanto independiente o trascendente al sujeto. Contrariamente, se hablará de la subjetividad de ciertas cualidades, en la medida en que ellas inhieran o pertenezcan al sujeto en cuanto sujeto o titular de actos de conocimiento, voluntad o sentimiento.

En un sentido similar a lo apuntado hasta ahora, Andrei Marmor, en su trabajo "Three Concepts of Objectivity", distingue entre la objetividad semántica, la metafísica y la lógica. En cuanto a la primera, que es la que aquí más interesa, sostiene que se refiere a ciertos tipos de discurso: aquellos que se refieren a un objeto en el mundo, independiente del sujeto; esta noción se contrapone semánticamente a subjetivo, que enuncia la referencia a un aspecto del propio yo, mental o emotivo. El filósofo israelí pone como ejemplo de subjetivismo en la ética a las doctrinas emotivistas, para las cuales las afirmaciones éticas se refieren sólo a estados emocionales del sujeto; en cambio, aparecen como representantes del objetivismo todas aquellas doctrinas éticas que sostienen que las afirmaciones morales no se reducen a la manifestación de meras opiniones o afecciones del sujeto, sino que tienen como referente semántico a un objeto de la realidad trascendente al sujeto. ${ }^{10}$

Un criterio sólo parcialmente similar sigue John Finnis en su libro Fundamentals of Ethics, en el que distingue entre las concepciones subjetivistas de la ética, para las cuales no existe algo así como la verdad o falsedad de las proposiciones práctico-morales, y las concepciones objetivistas, que afirman la posibilidad de conocer con verdad - verdad como adecuación o correspondencia - el contenido de las proposiciones éticas. ${ }^{11}$ En este punto, cabe destacar que si bien

10 Véase Marmor, A., "Three Concepts of Objectivity”, en Marmor, A. (ed,), Law and Interpretation, Oxford, Clarendon Press, 1995, pp. 177-201.

11 Véase Finnis, J., Fundamentals of Ethics, Oxford, Clarendon Press, 1983, pp. 56-66. 
-tal como lo evidencia Finnis- la cuestión de la objetividad de las proposiciones prácticas $-\mathrm{y}$, en rigor, de todo tipo de proposiciones - se vincula directamente con el problema de su verdad o falsedad, ${ }^{12}$ se dejará momentáneamente de lado este aspecto de la cuestión, para centrar la atención más que en la relación misma de adecuación o inadecuación del entendimiento al mundo real, en el carácter o índole del referente de las proposiciones jurídico-interpretativas.

En definitiva, en lo que sigue -y limitando la argumentación a las proposiciones jurídicas - se designará con la palabra objetividad a aquella cualidad de las proposiciones según la cual la medida de su corrección o de su validez radique en su adecuación o conmensuración con una realidad - de cualquier tipo que ésta sea - total o parcialmente independiente del sujeto que conoce. Dicho de otro modo, una proposición práctica —en especial, práctico-jurídicaserá objetiva cuando su corrección se conmensure o se mida por referencia a algo que de algún modo no dependa -al menos no exclusivamente- del pensamiento o del querer del sujeto que la piensa o expresa, v.gr., ciertas exigencias normativas de la naturaleza humana ${ }^{13}$ o determinadas prácticas jurídicas de la comunidad. Por el contrario, una proposición práctica cuya validez o corrección dependa de una instancia a su vez dependiente - total o parcialmentedel pensar o del querer del mismo sujeto, v.gr., de las emociones de los jueces o magistrados, no resultará propiamente objetiva, sino que será estrictamente subjetiva.

Aplicando estas nociones al ámbito de la i. jurídica, que es la que principalmente interesa en este contexto, las dos principales cuestiones a dilucidar son las siguientes: 1) la de saber si las proposiciones interpretativo-jurídicas tienen alguna referencia semántica más allá del texto mismo que

12 Véase, en este punto, González Ayesta, C., Hombre y verdad. Gnoseología y antropología del conocimiento en las Q.D. De Veritate, Pamplona, EUNSA, 2002.

13 Véase Murphy, M.C., Natural Law and Practical Rationality, Cambridge, Cambridge U.P., 2001, pp. 40 y ss. 
interpretan; ${ }^{14}$ y 2) la de conocer, en el caso de que la primera pregunta se responda afirmativamente, cuál es el término objetivo de esa referencia; en otras palabras, cuál es la realidad, o las propiedades de esa realidad, que son el objeto de la referencia semántico-jurídica y en qué consiste su objetividad.

Respecto de la segunda de estas cuestiones, que es la que se abordará en esta oportunidad, es posible distinguir, en el marco del debate contemporáneo, al menos cuatro posiciones principales: 1) la que niega la existencia de cualquier tipo de referencia objetiva más allá del texto del enunciado normativo interpretado; según estos autores, en el caso de existir alguna referencia, ella resultará meramente subjetiva; esta es la posición, v.gr., de los autores de impronta emotivista y puede ser calificada en este marco como subjetivista; 2) la de quienes reconocen la existencia de una cierta designación en las normas jurídicas interpretadas, pero que la colocan en alguna realidad directamente dependiente de la voluntad, el acuerdo o las prácticas de los sujetos jurídicos; es el caso de quienes proponen, como término objetivo de referencia de las normas, v.gr., a las prácticas, genéricamente consideradas, de los jueces de una comunidad; esta postura puede ser denominada como defendiendo una objetividad mínima; 3) la que corresponde a aquellos autores que aceptan la objetividad de la referencia de los enunciados jurídico-normativos y consideran a la objetividad mínima como insuficiente, proponiendo una objetividad que, si bien trasciende la llamada mínima, no va más allá de un cierta construcción discursiva o pragmática; esta concepción es denominada por Coleman y Leiter como objetividad modesta; y finalmente, 4) la que defiende no sólo el carácter referencial y objetivo de las enunciaciones normativas, sino que además sostiene que el objeto de esa referencia es, de algún modo verificable, una entidad o una

14 Esta cuestión ha sido abordada por el autor en un trabajo precedente: Massini-Correas, C. I., "La teoria referenziale-realista dell'interpretazione giuridica", Ars Interpretandi, Milán, núm. 8, 2003, pp. 449-476. 
propiedad realmente existente; esta posición puede ser denominada como objetivismo fuerte, o bien, objetivismo realista.

En lo que sigue, se estudiará con cierto detalle la propuesta de Coleman y Leiter de una objetividad modesta para los enunciados interpretativos, ${ }^{15}$ considerada por estos autores como superadora de las propuestas mínimas y fuertes; pero también se efectuarán algunas remisiones a las restantes posiciones, para concluir con una valoración critica de las diferentes opiniones en torno a la objetividad interpretativa y con un ensayo de elaboración sintética de una propuesta alternativa.

\section{LA OBJETIVIDAD DE LAS PROPOSICIONES INTERPRETATIVAS}

Pero antes de pasar al análisis de la propuesta de Coleman y Leiter, resulta conveniente plantear, aunque sea someramente, la siguiente cuestión preliminar: ¿es necesario hablar de objetividad en el caso de las proposiciones interpretativas prácticas?; en otras palabras, ¿tiene sentido o es razonable o necesario calificarlas como objetivas, descalificándolas cuando resultan meramente subjetivas?; o bien, ¿no basta, para la validez de una i. jurídica, con la referencia de las proposiciones interpretativas a las convicciones o emociones del sujeto interpretante? Finalmente: ¿por qué es necesario recurrir a la noción de objetividad en las interpretaciones, si bastaría con sostener que cada uno interpreta meramente según sus gustos, elecciones o convicciones, $i$. e., de modo meramente subjetivo?

La primera respuesta que debe darse a estas preguntas es que el mero subjetivismo resulta incapaz de explicar consistentemente el desacuerdo jurídico. ${ }^{16}$ En efecto, si las proposiciones interpretativas fueran meramente subjetivas,

15 Véase Coleman, J. y Leiter, B., "Determinacy, Objectivity and Authority" (en adelante DOA), en Marmor, A. (ed,), Law and Interpretation, Oxford, Clarendon Press, 1995, pp. 252 y ss.

16 Véase Rosati, C. S., "Some Puzzles About the Objectivity of Law", p. 12. 
carecería de todo sentido racional discutir o debatir acerca de la corrección o incorrección de una determinada i. jurídica. Ahora bien, es un hecho que las interpretaciones, i.e., las proposiciones que determinan el sentido normativo de un texto jurídico, se califican de hecho y casi sin excepción como buenas o malas, correctas o incorrectas, adecuadas e inadecuadas, todo ello con independencia de la opinión personal de jueces, juristas o simples legos. ${ }^{17}$ En otros términos: es evidente que no todas las interpretaciones aparecen como válidas, que no es lo mismo que el resultado de la actividad interpretativa sea la proposición Dxa o bien la proposición $\mathrm{Dxb},{ }^{18}$ lo que significa que el valor jurídico de dos interpretaciones contrarias o contradictorias no es ni mucho menos indiferente. Y los debates y discusiones que tienen lugar en el ámbito de la i. jurídica son la expresión de esta inexcusable posibilidad de desacuerdo racional.

Ahora bien, si existe un desacuerdo racional entre las distintas interpretaciones, ello implica necesariamente que existe la posibilidad de superarlo, lo que a su vez supone la existencia de un criterio conforme al cual establecer cuándo una afirmación supera la controversia, criterio que no puede reducirse a las opiniones subjetivas de cada uno de los contendientes, ya que ello implicaría la imposibilidad misma de la superación del desacuerdo. Es inexcusable remitirse, por lo tanto, a un criterio trascendente a las subjetividades de los querellantes, i.e., objetivo, para alcanzar la resolución de las controversias entre las diferentes y divergentes interpretaciones jurídicas.

Por otra parte, y éste es el segundo de los argumentos, si todas las interpretaciones tuvieran el mismo valor jurídico, no sería necesario recurrir ni a juicios, ni a jueces, ni a alambicadas argumentaciones, ni al asesoramiento de abogados, sino que bastaría con efectuar un simple sorteo en-

17 Véase Canale, D., Forme del limite nell'interpretazione giudiziale, Padova, CEDAM, 2003, pp. 67 y ss.

18 Véase Kalinowski, G., Introducción a la lógica jurídica, traducción de J. A. Casaubon, Buenos Aires, Eudeba, 1973, pp. 84 y ss. 
tre las posibles proposiciones interpretativas de un determinado texto legal, y las diferentes controversias juridicas se solucionarian de un modo mucho más rápido y sobre todo más económico. Pero es claro que esto significaria, lisa y llanamente, la desaparición de las prácticas jurídicas tal como las conocemos y su sustitución lisa y llana por la irracionalidad del azar o del capricho del brujo de la tribu. ${ }^{19}$

Pero además, y en tercer lugar, resulta patente que los castigos, penas, resarcimientos, privaciones de la propiedad y de la libertad y todo el resto de las sanciones juridicas no pueden justificarse meramente en la opinión personal, el sentimiento intimo o las emociones particulares de jueces, legisladores o administradores. Existe una evidente desproporción deóntica entre la imposición de la pena de privación de la libertad de por vida y el mero sentimiento ocasional y en definitiva, caprichoso, que puede experimentar un magistrado. Es claro en este punto, que sólo la remisión a un referente objetivo puede proporcionar una razón capaz de justificar suficientemente la imposición de un castigo como consecuencia de una i. jurídica. ${ }^{20}$

Finalmente, es indudable que los autores subjetivistas, en particular los emotivistas de distinta clase, cometen una reducción indebida cuando identifican una serie de proposiciones jurídicas objetivas del tipo "X es lo debido", con un conjunto diferente de proposiciones subjetivas del tipo " $\mathrm{X}$ me agrada". En efecto, las proposiciones interpretativas, v.gr., "el derecho prescribe que Juan devuelva el automóvil $\mathrm{x}$ a Pedro", revisten una intencionalidad objetiva, pretenden expresar lo que el mismo derecho establece; por lo tanto, no pueden ser identificadas, tal como lo hacen los emotivistas, con proposiciones tales como "me agrada que Juan devuelva a Pedro el automóvil x". La primera es evidentemente una proposición acerca del derecho, y por lo tanto objetiva,

19 Véase Marmor, A., "Three Concepts of Objectivity", en varios autores, Law and Interpretation, cit., nota 10, pp. 198 y ss.

20 Véase Massini Correas, C. I., Constructivismo ético y justicia procedimental en John Rawls, México, UNAM, 2004, pp. 44-48. 
mientras que la segunda es una proposición acerca de mí mismo, y por lo tanto subjetiva. ${ }^{21}$ De este modo, cualquier identificación de dos proposiciones de diferente género resulta lógicamente inaceptable y, por lo tanto, racionalmente ilegitima, por lo que no es posible reducir las proposiciones interpretativas jurídicas a proposiciones acerca de las emociones experimentadas por el sujeto que las formula.

\section{COLEMAN, LEITER Y LA OBJETIVIDAD INTERPRETATIVA "MODESTA"}

Por todo esto, resulta indudable que es necesario, en el ámbito del derecho, recurrir a alguna instancia objetiva, i.e., colocada más allá de la mera subjetividad, para establecer la corrección o adecuación de las diversas interpretaciones posibles de un texto jurídico. Pero una vez establecida esa conclusión, resulta imprescindible responder ahora a otro grupo de cuestiones, en especial a las siguientes: ¿esta objetividad inexcusable puede ser meramente débil, i.e., sólo relativa y limitadamente trascendente a la opinión subjetiva del autor de la i.?; en otras palabras: ¿es suficiente la mera superación de la intimidad del sujeto para alcanzar una fundamentación adecuada o proporcionada de las diferentes interpretaciones en el ámbito del derecho? Los autores recién citados, Jules Coleman y Brian Leiter, reconocen que una objetividad meramente débil no resulta una instancia de apelación suficiente como para fundar una determinada solución jurídica.

Si se supone que nuestras teorias han de iluminar nuestras prácticas - escriben - es importante hacer notar que la mayoría de nuestro discurso emplea predicados que invitan a interpretaciones objetivistas... En el discurso moral -en nuestras discusiones o debates en asuntos morales- no justificamos los juicios acerca de la moralidad de los actos alegando el hecho de que "la mayoría de la gente de por aquí cree que las co-

21 Véase Fagothey, A., Ética, México, McGraw-Hill, 1993. 
sas son así". Aún la superficie de nuestro discurso moral parece aspirar a formas más elevadas de objetividad. ${ }^{22}$

Más adelante, refiriéndose a la que denominan "objetividad mínima", i.e., la que se reduce a la remisión a datos tales como la opinión de la mayoría de los jueces, Coleman y Leiter sostienen que ella puede ser objeto de varias objeciones relevantes, una de las cuales se refiere a que "si las prácticas convencionales son las que fijan el sentido de una palabra, luego los participantes en dicha práctica no pueden estar nunca equivocados al usar esa palabra tal como lo hacen". ${ }^{23}$ Y como es un hecho que los jueces - y no sólo ellos - se equivocan, o al menos la enorme mayoría de las personas así lo considera, se está frente a una explicación errónea o insuficiente de la objetividad propia de las interpretaciones juridicas. Por otra parte - sostienen estos autores- si las reglas juridicas obligatorias fueran establecidas sólo por la opinión común de los operadores jurídicos, en el caso - muy frecuente, por otra parte- de que existiera algún desacuerdo acerca del contenido de esas reglas, se debería aceptar la conclusión de que esas reglas no existen lisa y llanamente.

Esto significa - escriben respecto a esa posibilidad- que en la medida en que existe un desacuerdo acerca de lo que una regla exige, no existe tampoco acción que sea requerida por ella; y esto es porque lo que la regla requiere resulta fijado sólo por la conducta convergente... En ausencia de esa convergencia, no existe deber alguno. ${ }^{24}$

Pero esta refutación, justificada y razonable, de las pretensiones de una objetividad mínima, no lleva a estos autores a la aceptación de una objetividad fuerte para las interpretaciones jurídicas; más aún, rechazan expresamente esa posibilidad, refiriéndose concretamente a la versión pro-

\footnotetext{
DOA, cit., nota 15, p. 254.

Ibidem, p. 262.

Ibidem, p. 263.
} 
puesta por Michael S. Moore y David O. Brink. En este punto, Coleman y Leiter caracterizan a las pretensiones de una objetividad fuerte para la interpretación jurídica, a las que incluyen en lo que denominan "realismo metafisico", 25 como sosteniendo la conjunción de dos premisas: "la primera que afirma la independencia de los hechos de nuestro acceso epistémico a ellos (su independencia de la evidencia y la creencia humana); la segunda, que afirma la posibilidad de asegurar o garantizar el conocimiento de esos hechos". ${ }^{26}$ Pero para estos autores, esta posición plantearía una dificultad aparentemente insalvable: "Si la existencia y naturaleza de los hechos jurídicos son independientes de todo lo que los juristas y jueces creen... ¿cómo entonces harán los jueces para tener acceso a ellas?27

Para Coleman y Leiter el realismo metafísico no puede responder a esta pregunta, ya que ninguna de las dos explicaciones que los realistas han propuesto para salvar la aporía resultan satisfactorias: 1) no lo es la propuesta por $\mathrm{Mi}$ chael S. Moore, ya que es meramente coherentista (una interpretación está justificada si resulta coherente con las restantes creencias que se tienen sobre el punto en cuestión), y esto significa abandonar en los hechos el realismo metafísico; 2) no lo es tampoco la respuesta de los realistas "externalistas" como Alvin Goldman, según la cual el conocimiento de algo resulta justificado cuando es causado por la realidad que se conoce, sin que sea necesario que el agente se dé cuenta de ello, ya que en el caso del conocimiento jurídico las interpretaciones se justifican en el interior de un proceso adjudicatorio, que es una actividad enteramente auto-consciente $\mathrm{y}$, por lo tanto, no hay lugar alli para un conocimiento causado externamente. ${ }^{28}$

25 Véase, sobre el concepto de realismo metafísico: Millán Puelles, A., Ética y realismo, Madrid, Rialp, 1995.

26 DOA, p. 256.

27 Ibidem, p. 257.

28 Ibidem, p. 259. 
Es entonces, frente a esta doble defectividad, tanto de las doctrinas minimalistas como de las realistas, que los autores estudiados proponen su versión de una objetividad modesta, capaz de superar las aporias planteadas por ambas doctrinas rivales. Esta objetividad consiste en que, para resultar justificada, una i. jurídica debe aparecer como correcta "bajo condiciones epistémicas ideales", es decir, cuando se ha arribado a ellas siguiendo un procedimiento cognoscitivo aceptado generalmente en nuestras prácticas como adecuado. "La objetividad modesta - escriben Coleman y Leiter - es una concepción normativa de la objetividad, en el sentido que ella provee un criterio para determinar si una adjudicación es legítima o justificable". ${ }^{29}$ Esta es la concepción - sostienen estos autores- defendida por Dworkin en Law's Empire y la seguida de hecho por la gran mayoría de la jurisprudencia contemporánea.

\section{LAS CONDICIONES EPISTÉMICAS IDEALES}

Ahora bien, al defender a la objetividad modesta, los iusfilósofos norteamericanos no pretenden - en primer lugarexponer una teoría general de la objetividad, ya que para ellos, "es posible pensar en una objetividad fuerte aplicable a los objetos físicos de tamaño mediano, como mesas y sillas, mientras se considera a la objetividad modesta como apropiada a nuestros conceptos en el dominio moral, social o jurídico". 30 Pero de todos modos, reconocen que "todas las concepciones de la objetividad -fuerte, modesta o mínima- suponen cortar la dependencia de cierta entidad o propiedad de los elementos de nuestra "subjetividad", como nuestras creencias, prejuicios, ideologías y características personales". 31

En cuanto al concepto mismo de objetividad modesta, los autores comienzan por rechazar a la que denominan "tesis

29 Ibidem, p. 272.

30 Ibidem, p. 265.

31 Ibidem, p. 266. 
relacional", según la cual existe una relación constitutiva entre la objetividad de la moral y la objetividad del derecho, es decir, que la objetividad en el ámbito moral es necesaria para la objetividad en el campo jurídico.

Nosotros - escriben- somos ambos positivistas, lo que significa que repudiamos la interpretación fuerte de la tesis relacional, es decir, el punto de vista de que la verdad de las afirmaciones jurídicas está invariable o generalmente relacionada con la verdad de ciertas afirmaciones morales. La objetividad del derecho es, desde nuestro punto de vista, independiente de la objetividad de la moral, en parte porque las condiciones de verdad de las proposiciones jurídicas no suponen la verdad de las proposiciones morales. ${ }^{32}$

Una vez rechazada esta tesis, los autores proponen su particular versión de la objetividad, al decir que "la objetividad de un concepto (por ejemplo, color, moralidad o derecho) presupone una práctica coherente respecto al uso de ese concepto. Sólo esas prácticas pueden admitir condiciones ideales de observación o juicio". ${ }^{33}$ Pero su preocupación central en este punto es diferenciar a esta posición objetivista modesta de cualquier convencionalismo: "Existe una diferencia, no obstante, entre decir que la naturaleza de $\mathrm{X}$ es determinada por lo que la comunidad cree acerca de $\mathrm{X}$ (convencionalismo u objetividad mínima) y decir que la naturaleza de $\mathrm{X}$ es determinada por aquello que la gente bajo condiciones apropiadas o ideales creeria sobre X". ${ }^{34} \mathrm{Y}$ para precisar aún más la noción, Coleman y Leiter enfatizan dos puntos más; el primero, que "en casos como estos, no tenemos otro modo de proceder que no sea el tratar de extraer (unpack) los conceptos que figuran en nuestras prácticas. El hecho de que estos conceptos figuren en nuestras prácticas no convierte a la tarea de extraerlos una versión del convencionalismo. Las prácticas pueden ser convencionales, pero esas prácticas convencionales pueden

\footnotetext{
32 Ibidem, p. 269.

33 Ibidem, p. 270.

34 Idem.
} 
estar comprometidas o implicadas (commited) con conceptos trascendentes a las prácticas o no convencionales". ${ }^{35} \mathrm{El}$ segundo es que las condiciones epistémicas ideales propias de la objetividad modesta, no son establecidas o fijadas por convenciones, sino que antes bien son descubiertas, son parte del concepto mismo de la realidad observada. ${ }^{36}$

Ahora bien, si se aplica esta concepción de la objetividad a los fenómenos jurídicos, se llega a la conclusión de que:

...los hechos jurídicos son modestamente objetivos cuando lo que sea un hecho jurídico es aquello que los jueces, bajo las condiciones epistémicas ideales, considerarian que es... Sugiriendo que este concepto de objetividad está implícito en nuestras prácticas jurídicas, estamos sosteniendo que, entre otras cosas, él puede proveer la mejor explicación para varios caracteres de esa práctica. ${ }^{37}$

Y llegado el momento de "descubrir" cuáles son concretamente esas condiciones epistémicas ideales, Coleman y Leiter afirman que ellas son en principio fáciles de identificar.

El juez ideal -escriben- debe ser: 1) completamente informado acerca de: a) toda la información factual relevante; y b) todas las fuentes jurídicas autoritativas...; 2) completamente racional, por ejemplo, observante de las reglas de la lógica; 3) libre de parcialidad personal a favor o en contra de las partes; 4) máximamente empatético e imaginativo, cuando el caso requiere, por ejemplo, el sopesar los intereses afectados; y 5) versado en y sensible con el conocimiento informal, cultural y social, que sea necesario para el razonamiento analógico... Nuestra afirmación - concluyen- es, entonces, que un juicio jurídico realizado bajo condiciones como estas, fijaría qué es el derecho en ese asunto. 38

Pero antes de finalizar este apartado, corresponde hacer referencia a una argumentación un tanto extraña que estos

\footnotetext{
Idem.

36 Ibidem, p. 271.

37 Idem.

38 Ibidem, p. 272
} 
autores incluyen en su exposición de la objetividad jurídica modesta: afirman que esta concepción de la objetividad supera el reclamo de los sostenedores de la objetividad fuerte, en el sentido que de existirian hechos jurídicos inaccesibles al conocimiento humano. "Hay que recordar - escribenque la objetividad modesta ha sido presentada como una objeción a la objetividad fuerte, en el sentido de que ésta considera a lo hechos legales en principio inaccesibles a los jueces, al mismo tiempo que la accesibilidad es considerada como una condición de la autoridad jurídica". ${ }^{39}$ Pero luego, en una nota al pie de página, los autores aclaran que, en realidad, "esto no supone que el punto de vista de que los hechos jurídicos de iure inaccesibles son incognoscibles para los humanos, sino más bien que el ser hechos jurídicos no depende de su ser cognoscibles". ${ }^{40}$

Finalmente, Coleman y Leiter concluyen su exposición de la objetividad jurídica modesta, con una sintesis de su intento argumentativo:

Tal como está concebido habitualmente -afirman- el debate sobre la objetividad en el derecho es un debate entre convencionalistas y realistas. Hemos tratado de mostrar que existe una concepción alternativa de la objetividad, la objetividad modesta, que explica la posibilidad de un error general y provee un sentido a los deberes jurídicos objetivos que va más allá de la conducta convergente, y que logra esto sin comprometerse con el realismo estricto acerca de los hechos jurídicos. ${ }^{41}$

\section{VALORACIÓN DE LA OBJETIVIDAD “MODESTA”}

Una vez expuesta brevemente la propuesta de Coleman y Leiter acerca de la objetividad de la i. jurídica, ${ }^{42}$ correspon-

39 Ibidem, p. 273.

40 Ibidem, p. $273 \mathrm{n}$

41 Ibidem, p. 273.

42 Sobre la filosofia jurídica de J. Coleman, véase, de ese autor, The Practice of Principle. In Defence of a Pragmatist Approach to Legal Theory, Oxford, Oxford U.P., 2001. 
de realizar una valoración de sus ideas en este punto, vinculándolas con las precisiones semánticas a las que se ha arribado en la primera parte de este estudio. La primera de las observaciones que corresponde hacer al abordar esta tarea, es la de hacer notar el reduccionismo en que incurren los autores al discutir las propuestas del realismo metafisico. En efecto, todas sus consideraciones se reducen a la refutación de las ideas, ya sea de Michel S. Moore, ya sea de los sostenedores del "externalismo", como Alvin Goldman y Peter Railton, pero en sus debates se encuentra ausente la línea principal del realismo metafísico, vale decir la orientación aristotélica que conforma lo que Robert P. George ha llamado la "tradición central de occidente", ${ }^{43}$ y para la cual el criterio de la objetividad de las interpretaciones no radica ni en la sola coherencia ni en la mera externalidad, sino en la adecuación del juicio práctico, en este caso un juicio producto de una i., con las exigencias del bien humano.

Esto significa que, en el marco de la "tradición central", la realidad a la que debe adecuarse la i. para resultar objetiva, no radica en unos "hechos morales" de carácter fáctico, que existen con absoluta independencia del conocer humano. Por el contrario, la realidad a la que debe adecuarse un conocimiento práctico para ser objetivo, i.e., verdadero prácticamente, es también una realidad práctica, una relación deóntica entre una conducta determinada y un bien humano, que para revestir carácter práctico o ético-práctico, ha de ser aprehendida y formulada en cuanto deóntica, i.e., prescrita, prohibida o permitida, por el entendimiento humano en su uso práctico. ${ }^{44}$ En este sentido, la realidad a la que ha de adecuarse el juicio práctico no es completamente independiente del entendimiento humano, ya que sólo ese entendimiento es capaz de captarla en cuanto debi-

43 George, R. P., Making Men Moral. Civil Liberties and Public Morality, Oxford, Clarendon Press, 1995, pp.19 y ss.

44 Véase Kalinowski, G., "La justification de la morale naturelle", en Bruaire, C. (ed.), La morale: sagesse et salut, París, Fayard, 1981, pp. 209-220. 
da, prohibida o permitida, i.e., en cuanto ética o jurídicamente exigida.

Es claro, no obstante, que la referencia objetiva de las proposiciones éticas o jurídicas, es una relación en cierta medida independiente del entendimiento humano, ya que es captada por el conocimiento práctico intencionalmente, i.e., como teniendo una existencia distinta del acto que las conoce; pero también es claro que esas relaciones adquieren carácter ético sólo al ser aprehendidas en cuanto tales por el hombre en el uso de su conocimiento práctico. ${ }^{45} \mathrm{Se}$ trata en este caso, por lo tanto, de objetos que en un cierto sentido - el sentido existencial- son independientes del conocimiento, pero que en otro sentido - el deóntico- no son independientes de su aprehensión por el entendimiento en su uso práctico. ${ }^{46}$ De aquí se sigue que la confutación intentada por Coleman y Leiter del realismo sólo puede ser esgrimida frente una de sus versiones, pero nunca frente a la doctrina sustentada por la corriente central del realismo ético y jurídico.

Pero por otra parte, no sólo resulta insuficiente la crítica dirigida a la objetividad fuerte o realista, sino que, además, la objetividad modesta propugnada por los autores norteamericanos resulta claramente insuficiente a la hora de justificar objetivamente las proposiciones jurídicas que son resultado del conocimiento interpretativo. Efectivamente, y en primer lugar, la modestia de la objetividad propuesta por Coleman y Leiter ha de trasladarse necesariamente, por una necesidad propia de la lógica, a la fuerza deóntica de las proposiciones juridicas producto de la i. Esto significa que las proposiciones jurídicas prudenciales habrán de resultar objetivamente fundadas sólo en un sentido también modesto, lo que resulta absolutamente insuficiente en el caso de las

\footnotetext{
45 Véase González, A. M., Moral, razón y naturaleza, Pamplona, Eunsa, 1998, pp. 142 y ss.

46 Véase Rohnheimer, M., Ley natural y razón práctica, traducción de M. Y. Espiña Campos, Pamplona, EUNSA, 2000, pp. 55 y ss. En contra de estas afirmaciones, véase Lisska, A., Aquina's Theory of Natural Law. An Analytic reconstruction, Oxford, Clarendon Press, 1997, pp. 195 y ss.
} 
proposiciones jurídicas, que plantean exigencias inexcusables, inexcepcionables y, en definitiva, fuertes. ${ }^{47}$

Pero no sólo resulta insuficiente la objetividad modesta para fundar racionalmente la fuerza deóntica de los preceptos jurídicos concretos, sino que esta versión de la objetividad termina reduciéndose en definitiva a una objetividad mínima y, por lo tanto, haciéndose objeto de las numerosas criticas que, justificadamente, se le han endilgado desde diferentes posiciones, entre ellas, la sustentada por los mismos Coleman y Leiter. Esto es así, toda vez que los autores estudiados sostienen que la objetividad modesta:

...admite la posibilidad de que todos puedan estar equivocados acerca de lo que una norma exige en un caso concreto; lo que parece correcto, aún para todos, acerca de lo que una norma requiere, puede no ser correcto. Sólo lo que aparece como correcto a los individuos colocados en la situación epistémica ideal determina lo que es correcto. Al mismo tiempo, la objetividad modesta provee un sentido en el cual las enunciaciones pueden ser objetivas que no depende de sus condiciones de verdad consideradas como completamente independientes de nuestros recursos epistémicos y de nuestro acceso a ellas. Como teoría metafisica - concluyenhace a la existencia y carácter de los hechos de diverso carácter dependientes de nosotros, pero no de nuestras actuales o existentes creencias o evidencias. ${ }^{48}$

Ahora bien, sucede que esta pretensión de una objetividad que es al mismo tiempo y en un cierto sentido dependiente del conocimiento y la actividad humana, pero en otro sentido no lo es, razón esta última por la que es precisamente objetivo, puede ser objeto de algunas observaciones decisivas. La primera de ellas es que la objetividad que pretenden Coleman y Leiter, aunque la planteen como independiente de las creencias y evidencias actuales o concre-

47 Véase Massini, Correas, C. I., Constructivismo ético y justicia procedimental en John Rawls, México, UNAM, 2004, pp. 120 y ss.

48 DOA, cit., nota 15, p. 264. 
tas de los actores juridicos individuales, lo que aparece como requisito de su objetividad, termina dependiendo en definitiva de las prácticas judiciales fácticas, y por consiguiente contingentes, de las que se extraen las condiciones epistémicas ideales de esa objetividad. Por lo tanto, si bien esa objetividad no depende inmediatamente de las convicciones actuales e individuales de los actores jurídicos, sí depende en definitiva de sus creencias consideradas genéricamente, que son las que determinan las prácticas judiciales de las que surgen las condiciones epistémicas ideales. Dicho de otro modo: si bien se alarga la estructura lógico-racional del fundamento decisivo de la objetividad, ésta termina siempre radicando en las convicciones o evidencias de los actores jurídicos, i.e., constituyendo una objetividad mínima o débil, con las deficiencias e insuficiencias que los mismos autores le reconocen.

Por otra parte, también se plantean dificultades aparentemente insalvables al momento de establecer con precisión el modo de acceder a las mencionadas condiciones epistémicas ideales. Coleman y Leiter sostienen que esas condiciones no son convencionales, sino que son descubiertas o identificadas en nuestras prácticas judiciales, ${ }^{49}$ pero aquí se presenta una alternativa: 1) o bien esas condiciones ideales son tales porque corresponden a una cierta "naturaleza" de la actividad judicial o de las realidades jurídicas, y entonces se cae en la repudiada metafísica realista; o bien, 2) esas condiciones ideales son de algún modo elaboradas por los sujetos, aunque sea colectivamente, sin ninguna referencia relevante a una realidad juridica independiente de sus convicciones o acuerdos y, en ese caso, se tratará necesariamente de una elaboración convencional y, por lo tanto, se arribará en definitiva a una objetividad débil o mínima que, como lo reconocen los mismos autores, resulta radicalmente insuficiente.

Pero todo esto es asi en definitiva porque, para estos autores y como ya lo hemos consignado anteriormente, "todas

49 Ibidem, p. 270. 
las concepciones de la objetividad... suponen (solamente) cortar la dependencia de cierta entidad o propiedad con elementos de nuestra "subjetividad", tales como nuestras creencias, prejuicios, ideologías y características personales", 50 dicho en otras palabras, se reduce el concepto de "objetividad" al de una mera "transubjetividad", i.e., a lo que sólo trasciende actualmente al sujeto, sin que sea necesario un cierto enraizamiento en un objeto o realidad independiente del mismo acto de conocer o valorar. ${ }^{51} \mathrm{Y}$ por ello, más que a una objetividad cabal, se termina adhiriendo a una subjetividad ampliada, ubicada no ya en el plano semántico sino en el pragmático, no en la referencia a estructuras de la realidad, sino más bien a ciertos usos lingüisticos o prácticas discursivas intersubjetivas. ${ }^{52}$ Pero resulta que estos usos y prácticas no alcanzan a constituir una objetividad radical, que establezca limites infranqueables para los sujetos jurídicos, y éste es, precisamente, el sentido de la búsqueda de la objetividad en las proposiciones normativas que son el resultado de la i. jurídica.

Dicho de otro modo, es posible distinguir aquí dos sentidos principales de la palabra "objetividad": (i) "objetividad" como mera trascendencia del sujeto, sin que esta calidad suponga un arraigo o referencia a un objeto o realidad independiente del sujeto o sujetos cognoscentes; y (ii) "objetividad" como inherencia a un objeto o realidad distinta radicalmente al sujeto o sujetos que conocen. En ese sentido, la proposición "es aceptado por todos que el homicidio debe castigarse", resultará objetiva sólo en el sentido (i), pero no en el sentido (ii). Y por su parte, la proposición "es una exigencia del bien humano que el homicidio sea castigado", será "objetiva tanto en el sentido (i), ya que tiene un funda-

50 Ibidem, p. 266.

51 Véase Agazzi, E., "Analogicità del concetto di scienza. Il problema del rigore e dell'objettività nelle scienze umane", en Possenti, V (ed.), Epistemologia e scienze umane, Milán, Massimo, 1979, pp. 69 y 70.

52 Sobre la noción de "pragmática" y sus alcances, véase Bertuccelli Papi, M., Qué es la pragmática, traducción de N. Cortés López, Barcelona, Paidós, 1996, pp. 71 y ss. 
mento que trasciende al sujeto, como en el sentido (ii), ya que hace referencia al bien humano considerado como una realidad en sí misma. Ahora bien, resulta que sólo la objetividad en el sentido (ii) es suficiente para fundamentar una exigencia que todos los hombres, aun considerados genéricamente, deban respetar, con independencia radical de sus preferencias, convicciones o elecciones. La objetividad en el sentido (i), por el contrario, si bien plantea una fundamentación del deber independiente de la voluntad o elección actuales de un sujeto determinado, no puede fundamentar una exigencia ética que trascienda la opinión o la voluntad de un conjunto o de la mayoría de los hombres. Y sucede que sólo en este caso la objetividad es capaz de mantenerse aún contra la posibilidad de error de todos los sujetos, que es para Coleman y Leiter, la condición de una auténtica objetividad.

Pero por sobre todo, la posición de estos autores da lugar a una perplejidad insuperable, ya que la aceptación de una objetividad distinta, tanto de la fuerte (naturalista o realista), cuanto de la mínima (convencional o consensual), supondría la posibilidad de un modo de existencia distinto, a la vez, del que corresponde a las realidades naturales, y del que compete a las convenciones, acuerdos o construcciones humanas, que sería el referente de la objetividad modesta. Dicho de otro modo, además de los entes naturales, dados a la experiencia humana, y de los culturales, construidos por el hombre, deberia existir una tercera categoría de entes, que se podrian denominar ideales y que existirian en un modo diverso de los dos anteriores; y sería este tipo de entidades la que garantizaría la objetividad modesta de las proposiciones jurídicas, en especial de las interpretativas.

Pero a esta conclusión necesaria de las premisas del objetivismo modesto, es necesario oponer una versión del 1lamado por John Mackie "argumento de la rareza" (o de la extrañeza) (argument of queerness), conforme al cual ese objetivismo supondría la existencia de "entidades o relaciones de un tipo sumamente extraño (queer), completamente 
diferentes de cualquier otra cosa en el universo".53 Mackie aplica esta objeción a todo tipo de objetividad ética, lo que no resulta estrictamente correcto, ${ }^{54}$ pero es evidente que esa argumentación puede ser aplicada para desmontar la construcción por Coleman y Leiter de un tercer modo de entidades, diversas de las que conocemos hasta ahora, que fundamentan su propuesta de una objetividad modesta para las proposiciones jurídicas.

En definitiva, este argumento, aplicado a la propuesta de los autores estudiados, puede formularse de la siguiente manera: en el universo existen dos clases de entidades: 1) las dadas en la naturaleza y 2) las elaboradas o construidas por el hombre o por algún tipo de animales. Hasta lo que podemos llegar a saber, en el mundo no hay más que esos dos tipos de realidades, por lo que la pretensión de suponer la existencia de un tercer tipo de realidades hasta ahora desconocidas, las que hemos llamado realidades ideales, resulta vana e injustificada, por lo que toda construcción sustentada sobre la base de esa existencia, ha de ser considerada ilusoria y engañosa. Este tipo de argumentación resulta en un cierto aspecto similar a la propuesta por los propulsores de la axiología de la primera mitad del siglo XX y puede por lo tanto ser objeto de las mismas objeciones que se levantaron contra esos pensadores, en particular la que sostiene que el "mundo de los valores" por ellos propuesto puede resultar muy interesante, pero tiene un inconveniente insalvable: no existe.

\section{CONCLUSIONES}

Una vez completada la crítica de la propuesta elaborada por Coleman y Leiter de una objetividad jurídica modesta, distinta de los modos de objetividad hasta ahora conocidos,

53 Mackie, J., Ethics: Inventing Right and Wrong, Harmondsworth, Penguin, 1977 , p. 38.

54 Véase Benn, P., Ethics, Londres, University College London Press, 1998, pp. 40 y ss. 
corresponde resumir en unas pocas afirmaciones las conclusiones que pueden extraerse de la argumentación desarrollada; ellas son las siguientes:

a) Ante todo, que la exigencia de objetividad es constitutiva de las proposiciones jurídico-interpretativas, como de todas las proposiciones éticas, ya que sólo una referencialidad objetiva es capaz de dar respuesta a varias de las cuestiones más fundamentales que se plantean a ese tipo de proposiciones, como v.gr. la referida a la posibilidad de un error generalizado en el caso de una determinada i. jurídica; por supuesto que esta inevitabilidad del objetivismo jurídico excluye la viabilidad racional de las posturas subjetivistas, v.gr., de las diversas versiones del emotivismo.

b) Una vez aceptada la necesidad de una referencia objetiva de las proposiciones jurídicas, en especial jurídico-interpretativas, es necesario discriminar y valorar las diversas doctrinas objetivistas que se han propuesto en el debate contemporáneo; en especial, reviste importancia la versión del objetivismo elaborada por Jules Coleman y Brian Leiter que, con la denominación de objetividad modesta, intenta plantear una vía media entre las versiones mínimas y fuertes de la objetividad jurídica.

c) No obstante la originalidad de la propuesta, la teoría elaborada por estos autores no alcanza a responder acabadamente a las cuestiones que motivan la exigencia de la objetividad de las proposiciones jurídicas; en especial, corresponde destacar las decisivas ambigüedades en que incurre la elaboración de esos autores, toda vez que al proponer una objetividad que es a la vez independiente y dependiente de la actividad y elecciones humanas, y que es al mismo tiempo descubierta en las prácticas jurídicas y construida en esas mismas prácticas, no se alcanzan a configurar los extremos teóricos exigidos por la problemática que se quiere resolver.

d) Finalmente, se ha hecho en el texto una referencia somera a la propuesta de una objetividad práctico-realista que, a la vez que reúne las ventajas de la objetividad fuerte, 
no se ve abocada a las perplejidades que presentan algunas de las versiones más difundidas de esa orientación y representa, por otra parte, una clara superación de los cuestionamientos de que son objeto las versiones débiles o minimas de la objetividad jurídica; esta propuesta, que se inscribe en la tradición central del pensamiento ético y jurídico de occidente, ha de ser desarrollada y explicitada en sus supuestos, implicaciones y consecuencias; pero esta tarea habrá de ser el objeto de otro trabajo que el autor ya tiene en elaboración avanzada. 